\title{
"DESVERTICALIZAÇÃO"/"TERCEIRIZAÇÃO" E AS RELAÇÕES DE SUBCONTRATAÇÃO NO COMPLEXO AUTOMOBILÍSTICO BRASILEIRO
}

\author{
João Amato Neto \\ Departamento de Engenharia de Produção- Escola Politécnica/USP
}

\begin{abstract}
O presente estudo tem por objetivo básico investigar, dentro do quadro de reestruturação da indústria mundial, quais são os principais fatores que têm motivado as grandes empresas a adotarem estratégias de "desintegração vertical", com a contrapartida de "terceirização" e "subcontratação" de pequenas empresas (fornecedoras de peças, componentes, etc.). Busca, ainda, entender este fenômeno a partir das estratégias da grande empresa industrial em busca de maior flexibilidade e tendo em vista o advento do novo paradigma de produção industrial, onde as relações inter-empresas sob a "filosofia" 'just-in-time' e de qualidade assegurada (qualidade total) passam a ganhar maior relevância. Inicialmente são apresentados alguns aspectos dessa problemática a nível da indústria automobilística mundial para, posteriormente, analisar-se, a partir da pesquisa de campo, o caso do complexo automobilístico brasileiro.
\end{abstract}

Palavras-chaves: desverticalização, terceirização, subcontratação, desintegração vertical.

\section{Introdução}

A partir do início da década de 80 verificou-se uma profunda transformação na indústria automobilística mundial como um todo, assim como nos padrões de interrelação entre as empresas fornecedoras de autopeças e montadoras, em particular. Tal transformação ocorreu basicamente, em função da significativa evolução da indústria japonesa, assim como em função do início do processo de ingresso em massa de automóveis importados do Japão e Europa no mercado norte-americano.

Até aquela época os fornecedores externos da indústria automobilística eram numerosos, operavam via-de-regra com contratos de curto prazo, mantinham relações superficiais com as montadoras e promoviam pouca competição com os fornecedores internos. A esta variedade de organização HELPER (1991a, b, c) atribui o nome de "estratégia baseada na saída" . Ao contrário, após o início da década de 80, passa a ocorrer grande fluxo de informações entre as partes envolvidas, diminuição relativa no 
número de fornecedores e sensível elevação da duração dos contratos, todas características da chamada "estratégia de diálogo".

A partir deste modelo, a autora acima referida busca, fundamentalmente, explicar as razões que têm levado as montadoras de automóveis, principalmente as norteamericanas, a abrirem mão de seu poder de monopsônio (ou oligopsônio) sobre seus fornecedores, procurando entender porque ocorre uma relação aparentemente inesperada entre integração vertical e incerteza, e o porquê do retorno por parte de um grande número de montadoras (principalmente as norte-americanas) ao antigo modelo de relacionamento com os fornecedores, baseado no "diálogo".

Nos primórdios da indústria automobilística o sistema predominante de interrelação entre empresas fornecedoras e a compradora era o baseado em "diálogo", fato evidentemente explicado pela imaturidade da então recente indústria. A própria "linha de montagem", criada por Henry Ford, trazia consigo alguns elementos intrínsecos que ajudam a entender aquele padrão de inter-relação entre as empresas, ou sejam: a padronização dos produtos ( o famoso modelo "T"-Preto), fabricados em larga escala, através de equipamentos dedicados e de base tecnológica eletro-mecânica.

Naquela época (anos 20) a fronteira entre as montadoras e os fornecedores era extremamente tênue. Havia pouca estabilidade no mercado automobilístico, as montadoras dependiam fortemente de fornecedores independentes, mas por outro lado, os pequenos fornecedores situavam-se numa posição extraordinariamente frágil, tanto do ponto de vista financeiro como sob o aspecto tecnológico.

Com a consolidação das grandes montadoras (anos 30 e 40) no entanto, os acordos baseados em diálogo, até então predominantes, entram em franca decadência. As duas grandes montadoras norte-americanas - a Ford e a GM - passavam a manufaturar cada vez mais suas próprias peças, isto é, eram empresas altamente verticalizadas do ponto de vista de seus respectivos sistemas de produção. Tal situação implicava, conseqüentemente, em grande instabilidade nos acordos com os fornecedores independentes.

O passo seguinte foi o estabelecimento de acordos de diálogo com os fornecedores internos e da estratégia de saída com fornecedores externos. Na década de 40 a verticalização nas grandes montadoras havia atingido níveis exageradamente elevados, como resultado da grande ênfase na estratégia de saída, o que provocava óbvios sinais de ineficiência para a indústria automobilística como um todo .

Cabe ressaltar aqui que todo este processo levou à consolidação nas décadas seguintes, de uma indústria de componentes altamente concorrencial.

Já a partir da década de 50 uma nova configuração se apresentava para as relações de fornecimento. A estratégia tradicionalmente praticada pelas montadoras norte-americanas estava "baseada em saída" ('exit-based strategy'), pelo fato da montadora freqüentemente ameaçar seu(s) fornecedor(es) com o rompimento ou não renovação do contrato. Naquele contexto, a empresa compradora operava sempre de modo a ter acesso a muitos fornecedores intercambiáveis, apresentando baixa coordenação administrativa (freqüentemente o mercado era o único coordenador entre as partes envolvidas em um processo de negociação) e um sistema de incentivos aos fornecedores muito instável, dado o perfil de curto prazo dos contratos firmados. $\mathrm{O}$ 
baixo grau de comprometimento entre as partes constitui-se, certamente, no elemento fundamental para se entender a lógica de funcionamento deste tipo de relação baseado em "ameaças" de saída por parte do comprador.

Desta forma a principal vantagem para a adoção desta estratégia ("baseada em saída") por parte da montadora era o elevado grau de barganha que ela propicia. Por outro lado, a mesma estratégia cria fortes dificuldades para a mudança tecnológica.

A adoção enfática da estratégia baseada em saída e o isolamento relativamente à concorrência externa, levou as três grandes montadoras norte-americanas a uma relação estagnante para com seus fornecedores subsidiários, a ponto de alguns (fornecedores) chegarem a deter um altíssimo poder de barganha, pois, segundo a orientação então vigente, os componentes fundamentais deveriam ser montados no âmbito interno da organização, a fim de assegurar seu fornecimento. Ainda assim, as montadoras ocupam uma posição francamente favorável na divisão organizacional do trabalho, impedindo que seus fornecedores adquiram algum grau de autonomia, que lhes possa propiciar os benefícios advindos da inovação. Contudo a excessiva ênfase neste modelo levou ao prejuízo do controle da qualidade e à estagnação tecnológica, que é parcialmente contornada pela busca do "diálogo com traição", onde a montadora tenta usufruir da capacitação tecnológica do fornecedor e ao mesmo tempo manter alto seu poder de barganha.

Delineou-se desta forma uma configuração claramente dual, com forte integração vertical no âmbito dos fornecedores internos e com acordos "baseados em saída" no âmbito dos fornecedores externos à organização. Tal configuração levou as montadoras americanas a desfrutarem de uma posição doméstica extremamente confortável, mas simultaneamente as deixou muito vulneráveis ao ingresso de carros importados, tecnologicamente mais evoluídos (especialmente os fabricantes japoneses, que passaram a operar com seus respectivos fornecedores, a partir de "acordos de diálogo"), o que as levou (as montadoras norte-americanas) a um processo de resgate da relação de diálogo na década de 80 e neste início dos anos 90 .

Apesar disso as montadoras não se encontram, ainda, plenamente comprometidas com o sistema de diálogo, o que faz com que algumas relações com fornecedores sejam denominadas "nova saída", que difere da antiga relação, principalmente pelo prazo mais longo de contrato, e que concede uma certa estabilidade temporal aos fornecedores. Esta estratégia pode ser viável a curto prazo, dada a presença atual de muitos fabricantes de autopeças japoneses nos EUA e à melhor capacitação por parte dos NICs na produção de componentes de baixo custo.

\section{A Reestruturação das Relações Contratuais}

Todas as recentes análises (HOFFMAN \& KAPLINSKY, 1989; HELPER, 1991a, 1991b; WOMACK et al., 1990) que buscam detectar as diferenças e os contrastes das relações montadoras-fornecedores entre as indústrias japonesas, americanas e européias apontam, em geral, para o ponto de que tais diferenças são, 
provavelmente, mais acentuadas no aspecto das relações contratuais entre as empresas envolvidas .

No caso do Japão, em especial, o aspecto mais conhecido das relações de fornecimento são os contratos a longo prazo, que são implementados, via-de-regra, sob uma atmosfera de confiança múltipla. Dentre vários outros, esse aspecto constituise em um dos elementos vitais que podem melhor elucidar o funcionamento eficiente do modelo japonês da organização industrial e da produção.

Já nos Estados Unidos e na Europa, as relações contratuais continuam sendo, na maioria dos casos, tradicionalmente conflituosas, prevalecendo os contratos a curto prazo. Além disso, muitos componentes continuam sendo procurados pelas grandes empresas a partir de "fontes múltiplas de fornecimento" (um grande número de firmas fornecedoras de um mesmo item). E é justamente esta situação que tem favorecido, sobremaneira, as montadoras no sentido de imporem seus preços aos seus fornecedores e, também, de manterem controle sobre a tecnologia, reduzindo, portanto, sua dependência sobre o que elas (montadoras) percebiam como sendo uma espécie de "sócios não confiáveis".

Tendo como objetivo primordial a obtenção da "qualidade total", as montadoras americanas e européias parecem, agora, terem reconhecido a necessidade de mudança na base de suas relações com seus respectivos fornecedores. Essa mudança na natureza das relações contratuais de montadoras/fornecedores apresenta as seguintes dimensões (HOFFMAN \& KAPLINSKY, 1989):

1-) Uma mudança dos contratos de curto para longo prazo;

2-) Uma redução do fornecimento de "fonte (origem) múltipla", para poucos fornecedores capacitados.

3-) Uma sensível elevação no fornecimento de "fonte única", que deverá ser, necessariamente, acompanhado de uma variedade de novas formas de relacionamento; e como resultado dos anteriores, uma redução deliberada do número total de diferentes fornecedores contratados pelas montadoras.

Desta forma, pode-se afirmar que, junto com a mudança de ênfase qualidade/preço, descrita acima, estas relações contratuais representam a maior mudança organizacional pela qual passou a indústria automobilística norte-americana, desde a reforma de Sloan na GM no início dos anos 20 (WOMACK et al., 1990).

Porém, uma vez que tais mudanças ainda estão em evolução é difícil julgar o grau de progresso. Ainda assim, pode-se assumir que o movimento para uma "fonte única" de fornecimento é quiçá mais pronunciado. As empresas norte-americanas estão anunciando suas políticas neste sentido já há quase uma década, sem terem apresentado, ainda, ganhos significativos até os anos mais recentes.

A situação é bem diferente na Europa, onde no passado já houve um grande número de "fontes únicas" de fornecimento. Isto se explica pela existência de apenas um fornecedor para um determinado insumo, ou porque já existia igualdade de relações entre montadoras e fornecedores (p.ex. Fiat montadora e "FIAT componenti"), ou porque elas já entendiam que qualquer mudança rumo à produção JIT, simplesmente não poderia sobreviver sob o antigo regime de "fonte-múltipla" e 
de corte no preço de competição. Portanto, tanto nos EUA como na Europa, as mudanças nas relações contratuais estão sendo acompanhadas por mudanças impostas pelas montadoras em outras dimensões da relação montador/fornecedor.

\section{A Complexidade Tecnológica e a Importância da "Qualidade Total"}

Uma das principais mudanças verificadas nos últimos anos aponta para o fato de que o processo de seleção de fornecedores tem-se tornado mais complexo e rigoroso. Neste sentido a importância relativa das variáveis de negociação - preço e prazo de entrega - tem diminuído. Em contrapartida há uma ênfase maior para os aspectos da qualidade e da capacitação tecnológica no estabelecimento de critérios de seleção dos fornecedores. Vale a pena salientar, em tempo, que estes critérios já são amplamente difundidos no complexo automobilístico japonês, enquanto que nos Estados Unidos e na Europa tais mudanças já estão em curso.

Uma recente pesquisa sobre a "Reestruturação das relações montadorafornecedor e sobre a capacitação tecnológica na indústria de componentes dos Estados Unidos e da Europa Ocidental" (HOFFMAN \& KAPLINSKY, 1989), revelou que onde as firmas de componentes sentiram maior pressão para mudar, foi precisamente dentro da área organizacional. Isto é particularmente verdade nos Estados Unidos, onde cada aspecto da relação montadora-fornecedor parece estar numa situação crítica e destinada a mudar em direção diferente daquela do passado.

Um dos aspectos mais notáveis desse processo de mudança aponta para o fato de que tem havido constante pressão por parte das montadoras para que seus fornecedores busquem constantemente incrementar a qualidade das peças e componentes. Tais pressões se manifestam de várias formas, sendo que a maioria das montadoras têm estabelecido algum tipo de "programa de verificação da qualidade". Há um padrão mínimo para a aceitação de um lote de matériasprimas/peças/componentes, e este padrão tende a ser cada vez mais rigoroso.

Cabe salientar, entretanto, que já desde o início dos anos 80, algumas montadoras européias já haviam estabelecido padrões de qualidade junto aos seus fornecedores, padrões estes que deveriam ser atingidos por todos os fornecedores até o final de 1985, caso contrário seus respectivos contratos seriam cancelados. O primeiro destes padrões foi um tanto quanto subjetivo, ou seja: Em um primeiro momento os engenheiros da FIAT visitaram as linhas de produção de seus fornecedores para fixar um nível de qualidade e comparar com os de seus competidores; no segundo momento, eles (engenheiros da FIAT) solicitaram aos auditores um certo nível de qualidade independente para checar os componentes; e a FIAT estimou que em 1985 a qualidade de seus componentes era 30\% melhor do que em 1983. Ocorre, porém, que a FIAT ainda havia avaliado seus próprios fornecedores, naquela época, a um nível mais baixo do que as montadoras japonesas já faziam há alguns anos.

Ainda do ponto de vista das estratégias de "qualidade total" ou "qualidade assegurada" sabe-se que a chave do sucesso na implantação das técnicas de controle de qualidade, que estavam sendo exigidas pelas montadoras japonesas, era o uso do 
"controle estatístico de processo (CEP)". HOFFMAN \& KAPLINSKY (1989) revelam que todas as montadoras americanas entrevistadas estabeleceram, recentemente, programas de treinamento para instruir fornecedores no uso dessa técnica. Por outro lado, pode-se entender que a principal implicação dessa tendência (rumo a elevar a qualidade dos componentes) para a indústria automobilística mundial, traduz-se no fato de que a "qualidade" está se tornando, provavelmente, numa espécie de "força" por detrás das melhorias da produtividade e a redução do custo.

\section{A Tendência à Montagem de Sistemas e de Subsistemas}

Além dos vários aspectos já mencionados anteriormente, um novo esquema de montagem do produto final parece estar se delineando na indústria automobilística. $\mathrm{O}$ movimento rumo à sub-montagem "off-line" de sistemas e subsistemas de componentes, traduz uma série de vantagens à montadora do produto final: menores estoques em processo, menor espaço físico de fábrica (em consequência da anterior , menores custos com mão-de-obra direta (trabalhadores de linha) e, também com mãode-obra indireta (supervisão, média gerência), maior flexibilidade ao processo produtivo, etc. Agora o objetivo básico é montar amplos subsistemas "off-line" e encaminhar estes rumo à montagem final para instalação como um sistema, em lugar de comprar componentes individuais e instalar na linha de montagem final.

Esta tendência traz, por outro lado, a exigência de maior confiabilidade por parte da empresa compradora, em função da maior complexidade dos insumos adquiridos. Reforça-se, assim, a necessidade de se estabelecer programas de "qualidade totalmente assegurada" junto aos fornecedores destes subsistemas. Tal tendência tem suas implicações tanto para o desenho ("desenho modular") dos componentes como para a interface sistemas/produto final.

Finalmente, a tendência rumo ao desenho modular tem uma série de outras implicações importantes:

10) Para que esse novo arranjo inter-empresas possa funcionar a contento é necessária uma nova forma de relação contratual e de trabalho entre montadoras e fornecedores. Isto explica o grande empenho por parte das montadores rumo ao contrato do tipo "longo prazo/fonte-única".

$2^{0}$ ) Outra conseqüência derivada desta tendência é que tais mudanças impostas pelas montadoras estão forçando a uma mudança rumo a uma maior "intensidade tecnológica" por parte dos fornecedores. As montadoras esperam, agora, que os seus fornecedores assumam grande parte do peso da engenharia de produto, mais do que no passado. Isto não implica apenas maiores investimentos em P e D por parte dos fornecedores, mas também desenvolver o trabalho de uma maneira diferente, voltada para a "engenharia de sistemas". Sob a perspectiva da montadora há, também, uma boa economia de custos, que se obtém a partir desta transição. Uma montadora sugeriu que, por mudar a engenharia de componente para o fornecedor, ela economizaria sobre o custo unitário da engenharia, a partir da constatação de que o 
custo "in-house" do componente engenharia (pela montadora) chegasse a ser 2 ou 3 vezes maior do que o feito pela firma de componentes (HOFFMAN \& KAPLINSKY, 1989).

30) Além do incremento dos investimentos em $\mathrm{P}$ e $\mathrm{D}$, há ainda, outras manifestações da intensidade do crescimento tecnológico, que inclui o incremento, cada vez maior, do número de 'joint-ventures' com o propósito de compartilhar os custos e ganhos do avanço tecnológico, e a rápida expansão da conexão interempresas, baseada na informática e nas telecomunicações, que servem não apenas ao incremento no pedido de peças e cronograma, mas também no uso compartilhado de base de dados e do CAD integrado.

$\left.4^{0}\right)$ Outro aspecto, além desta tendência rumo a uma maior integração do sistema, é de natureza puramente tecnológica, ou seja: as novas tecnologias de produto, que envolvem a microeletrônica e novos materiais jogam um papel importante como facilitador para uma mudança "técnico-sistêmica".

\section{A Tendência Rumo à Produção 'Just-in-Time'}

A busca permanente de otimização do processo produtivo tem norteado a indústria moderna neste final de século. Em particular naqueles setores mais dinâmicos e competitivos do setor industrial, a busca de maior eficácia nos sistemas de produção e de maior produtividade nos seus vários processos torna-se uma exigência cada vez maior para aquelas empresas que desejam manter/incrementar o seu poder de competitividade. Neste sentido é que a "filosofia" de produção 'just-in-time' (JIT) ganha um destaque especial, particularmente para as empresas do setor automobilístico.

O JIT é tradicionalmente conhecido como um sistema de produção que tem por princípio o "zero estoques". Entretanto, na realidade o JIT é muito mais do que um sistema de minimização de estoques. Com sua ênfase maior sobre flexibilidade, mínimo desperdício e pequeno lote de produção, ele está se tornando o novo princípio de organização da produção em indústrias montadoras nos anos 90, superando inclusive, o paradigma fordista de 'just-in-case' que dominou o antigo padrão de industrialização, ao longo da primeira metade deste século. Porém o ritmo e a intensidade de sua difusão através da indústria automobilística mundial tem ocorrido de forma heterogênea.

Um dos aspectos mais importantes em se tratando das possibilidades de difusão do sistema JIT nas relações inter-empresas aponta para a necessidade de aproximação física/geográfica das plantas da "empresa-mãe" (montadora) das plantas de seus principais fornecedores ("fornecedores de primeira linha").

Por outro lado, já está bastante difundido pela indústria automobilística ocidental o uso de sistemas de comunicação 'on line' entre fornecedores e montadoras.

\section{Diferentes Modalidades de Aprovisionamento (Suprimento de Componentes)}


CHANARON et al. (1993), propõem uma tipologia para os "princípios diferenciados das modalidades de aprovisionamento" na indústria automobilística, como mostra o quadro da página seguinte.

O primeiro caso (modo de subcontratação) constitui-se na forma mais tradicional de aprovisionamento e está centrado no critério do preço mínimo que o cliente (montadora) pode obter através de elevados volumes de peças/componentes adquiridos de um grande número de fornecedores ("pulverização no fornecimento"). Há neste caso uma dominação total da montadora/cliente sobre seus fornecedores, o que se traduz por um tipo de relacionamento bem próximo ao modelo "fordista" de relações entre empresas, com divisão e especialização de tarefas (ao invés de cooperação) e uma nítida separação entre concepção e fabricação do produto. O resultado final de todo esse conjunto de práticas tem sido um processo constante de enfraquecimento dos fornecedores, com freqüentes atrasos na entrega dos pedidos (oferta sempre inferior à demanda), baixos níveis de qualidade das peças fornecidas, etc.. 
Quadro: Os Diferenciados dos Modos de Fornecimento

Fonte:CHANARON et al. (1993).

Aprovisionamento na Indústria Automobilística Mundial

1.) Modo de Subcontratação (Clássico)

Critério preço mínimo / Fracas relações montadora-fornecedor

"Pulverização" no fornecimento /Total dominação da montadora

* Modo predominante no paradigma de produção "em massa"

2.) Modo de "Parcerias"

Critério da "confiança mútua" entre fornecedor e montadora

Princípios de "Excelência" e "Qualidade"

Maior aproximação geográfica com os fornecedores

Prioridade para a montagem de subsistemas

* Modo predominante na Ind. Automobilística Japonesa

3.) Modo de Mercado

Baseado nas relações clássicas de mercado concorrencial

Não há compromisso formal de fornecimento

* Modelo "Anglo-Saxão" (Inglaterra, Estados Unidos, Canadá) 
(Levou à criação de grandes ETN's de Sistemas de peças/componentes motores, caixas-de-engrenagens, etc.)

Já o modelo (modo) de "parcerias" se difere de modo notável do anterior. Os critérios de fornecimento são mais complexos e baseados na confiança mútua entre fornecedores e clientes. Neste caso, os princípios de "excelência" e "qualidade assegurada" ganham predominância sobre a variável preço. Fornecedor e cliente buscam em conjunto estabelecer prazos de entrega de forma sincronizada, a fim de atingirem uma situação próxima ao sistema 'just-in-time' de aprovisionamento ("sem estoques"). Há nestes casos, via-de-regra, uma maior aproximação geográfica dos fornecedores com seus clientes, o que propicia uma maior capacidade e mobilidade no fornecimento. Prevalece, assim, o princípio de "partilha" de responsabilidades técnica, industrial (de produção), e comercial, assim como são também partilhados os ganhos de produtividade e os lucros advindos desta parceria. Esse modelo pode, em síntese, ser representado pela indústria automobilística japonesa, segundo o autor (CHANARON et al., 1993).

Por fim, a terceira forma de aprovisionamento refere-se à modalidade "de mercado", que se aproxima mais dos padrões praticados pela indústria automobilística da Inglaterra, Estados Unidos e Canadá ("modelo anglo-saxão"). Nesta forma prevalecem as relações clássicas de mercado concorrencial, não havendo qualquer compromisso formal entre as partes envolvidas no fornecimento. Este modelo levou à constituição de grandes grupos transnacionais especializados no fornecimento de vários sistemas de peças e componentes mais complexos, tais como: motores, caixas-de-câmbio, sistemas de suspensão, etc. (Perkins, Cummins, Rockwell, $\mathrm{ZF}$, dentre outros).

Em síntese, os autores anteriormente citados (CHANARON et al., 1993) concluem que há uma forte tendência mundial no sentido de que outras modalidades de aprovisionamento sejam paulatinamente substituídas pelo "modo de parcerias", tendo em vista os excelentes resultados já apresentados por este tipo de aprovisionamento na indústria automobilística japonesa.

\section{A Pesquisa de Campo- O "Complexo Automobilístico Brasileiro"}

A amostra analisada, através de pesquisa de campo, compõe-se de $\mathbf{5}$ montadoras (de automóveis, comerciais leves, caminhões e ônibus) e 8 fabricantes de autopeças, sendo que, nesse segundo grupo, a maioria das empresas compõem o $\mathbf{1 0}$. nível da "pirâmide" de subcontratação, ou seja, são fabricantes de sistemas e subsistemas de peças mais complexas, tais como sistema de freios , amortecedores, caixas-de-câmbio, rolamentos, motores, barras de direção, etc). Cabe salientar, em tempo, que a amostra procurou privilegiar empresas de significativa participação em seus respectivos segmentos de mercado e com capacitações técnica/gerencial diferenciadas em relação às demais empresas do setor.

\subsection{Grupo 1 - Montadoras}


Deste grupo de empresas que abrange, praticamente, todo o universo de fabricantes de automóveis de passeio, caminhões e ônibus pode-se constatar que, em linhas gerais, todas elas têm, de uma forma explícita ou não, uma "estratégia de desverticalização". Porém a extensão e a profundidade com que tais estratégias são conduzidas diferem de forma significativa uma das outras.

Enquanto que, por exemplo, algumas montadoras (MTD-1 e MTD-2) definem claramente suas opções por buscarem um estágio mais avançado de uma estrutura de "produção racionalizada", outra, a MTD-5 defronta-se, ainda hoje, com uma estrutura produtiva altamente verticalizada, chegando-se a produzir cerca de $60 \%$ do conjunto de ítens utilizados na montagem final dos veículos ( chegando a 100\% nos casos do motor, eixos, caixas de engrenagens e carrocerias ).

As montadoras de veículos de passeio em geral, estão desenvolvendo suas "estratégias de desverticalização" em um ritmo mais acelerado, tendo por objetivo final se tornarem, de fato, apenas montadoras de um conjunto de peças componentes, adquiridos junto aos mais diferentes tipos de fornecedores. Em outras palavras: a maioria das montadoras trabalham no sentido de se "especializarem" em seu "negócio central" ("core business"), deixando para terceiros as tarefas de fabricação, propriamente dita.

Entretanto, ainda hoje, há uma significativa parcela de peças e de subconjunto de componentes que continuam sendo produzidos internamente a essas grandes "empresas-mãe". Tais peças e subconjuntos referem-se, principalmente, aos itens: motor, sistemas de transmissão (câmbio, etc), sistemas de suspensão e alguns itens de segurança vital do automóvel, tais como a coluna de direção.

\subsubsection{Estratégia de "Desverticalização/Terceirização"}

Quanto aos responsáveis pela condução das estratégias de desverticalização/terceirização que, para efeito deste trabalho, incluem as decisões "enxugamento" do quadro de pessoal, e pela contratação de "terceiros" ou de "parceiros" há uma convergência de opções dentre as várias empresas pesquisadas, ou seja: alta direção, conjuntamente com um colegiado, composto em geral pela alta gerência financeira, de manufatura e de R.H., tomam as decisões. Na maioria das vezes, também, a média gerência participa na fase operacional.

No caso de "parcerias", em especial, as estratégias parecem estar em um estágio mais avançado. A empresa MTD-1 já opera com cerca de 15 "parceiros", que são fornecedores de peças/componentes totalmente engajados ao "PROJETO J" (JIT: proximidade, 'lealdade' no fornecimento, apresentar planilhas transparentes de custos). Para os próximos anos, o objetivo é o de se atingir 80 empresas participantes deste "PROJETO". 
Ainda em se tratando de "parcerias", a empresa MDT-2 tem procurado desenvolver pequenos fornecedores (de até 100 funcionários) através de programas de "melhorias de Qualidade e Produtividade", com apoio do SEBRAE (Serviço Brasileiro de Apoio às Micro e Pequenas Empresas).

Dentre os vários setores da empresa, os que estão mais envolvidos com "parcerias" são os de P \& D (a MTD-1 está desenvolvendo programas de "Engenharia Simultânea" e de "CODESIGN" e a MTD-2, a "Engenharia Cooperativa", fornecendo as especificações ao fornecedor que, a partir delas, detalha e executa). Em segundo plano, o setor de produção (manufatura), embora com intensidade ainda menor.

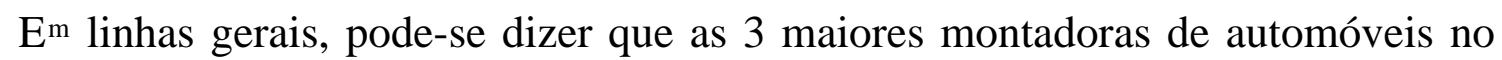
Brasil já são empresas bastante "desverticalizadas", atingindo, em média, um índice médio de 65\% a 70\% de "fornecimento externo" ("outsourcing"), em relação ao "valor total agregado" ao produto final.

Curiosamente, uma pequena montadora - MTD-4 - apresentou o menor índice de fornecimento externo, $20 \%$.

Dentre as 3 maiores montadoras, apenas uma delas (MDT-2) afirmou (através de seu gerente de compras) ter intenção de se atingir em breve um maior índice de "desverticalização" (72\% para automóveis e 87\% para caminhões até 1995).

Do ponto de vista dos motivos que, historicamente, levaram as montadoras a operarem com uma estrutura organizacional e produtiva mais verticalizada do que a atual, a maioria delas concorda com o fato de que na época de suas respectivas fundações (instalações iniciais), durante as décadas de 50 e 60 em geral (exceto a MTD-1 que foi implantada no início da década de 70 com uma estrutura mais "desverticalizada" do que as outras), não havia fornecedores confiáveis, isto é, devido à própria limitação e imaturidade da indústria automobilística no Brasil de então, o número de fornecedores de autopeças era bastante reduzido e os existentes não possuiam capacitação tecnológica suficiente para fornecer peças/componentes com "Qualidade Assegurada".

Atualmente, porém, a situação mudou significativamente. Já há um grande número de "fornecedores confiáveis" que buscam aprimorar a qualidade de suas peças/componentes através dos programas de "Qualidade Assegurada" (ISO 9000 e outros similares). Em alguns casos, o índice de "fornecedores capazes" atinge a 90\% do número de empresas subcontratadas, como no caso da montadora MTD-2.

Quando se procura as razões e as justificativas que têm levado as grandes montadoras a adotarem algum tipo de estratégia de "desverticalização/terceirização", verifica-se que a principal delas é a de propiciar à empresa como um todo um maior grau de flexibilidade em suas operações e atividades. Logo em seguida o motivo 
mencionado com maior freqüência refere-se ao objetivo de melhorar a qualidade das peças componentes adquiridos. A redução dos custos fixos, referentes às instalações, equipamentos, etc, aparece, em seguida, como outra justificativa para as empresas procurarem jogar para terceiros parte de suas atividades.

Em vários casos, também, foi citado o objetivo de redução de custos de mão-deobra indireta (Gerência e Supervisão).

Quanto à perspectiva de redução do número de fornecedores por tipo de item adquirido pelas montadoras, todas elas reafirmaram a intenção de se atingir a situação de um único fornecedor (altamente qualificado, evidentemente) por tipo de peça/componente comprado de terceiros. A idéia aqui, como expressa claramente pela MTD-2 é a de se atingir o "fornecimento único" ('single source'), tendo em vista reduzir o "grau de variabilidade" no fornecimento.

Cabe frisar, ainda, que essa estratégia parece ser bem mais dirigida para o grupo de fornecedores dos chamados componentes centrais, tais como o motor, os sistemas de transmissão, caixa de câmbio, dentre outras, em função, logicamente, do grau de complexidade tecnológica inerente à fabricação dos mesmos. Na realidade, em algumas montadoras, isto já é uma realidade (como é o caso da MTD-1 ).

Os critérios adotados pelas montadoras para a elaboração de um plano de compras junto aos seus fornecedores privilegiam de forma praticamente indistinta os parâmetros: preço, pontualidade na entrega (dos lotes encomendados), qualidade e assistência técnica.

\subsubsection{Sistemas de Informação}

Sabe-se que, através da experiência internacional (anteriormente relatada), toda e qualquer estratégia bem sucedida de "desverticalização/terceirização" deve se sustentar sobre sistemas eficientes de troca de informações (telecomunicações, redes de computadores 'on line', etc) entre fornecedores e empresas "clientes". Nesse aspecto, entretanto, o segmento das montadoras de automóveis no Brasil encontra-se, ainda, em um estágio incipiente. Das empresas entrevistadas, a MTD-1 possui sistemas interligados para troca de informações (sobre nível de estoques, programação da produção, datas, etc) junto a cerca de $25 \%$ do total de fornecedores atuais, enquanto que a MTD-2 já apresenta um quadro bem mais favorável nesse aspecto: já possui sistemas de informação 'on-line' com mais de $60 \%$ de seus fornecedores.

Entretanto, em relação à existência do "CAD-INTEGRADO" com fornecedores, apenas a MTD-2 afirmou possuir tal sistema (e tem planos de implantanção, em dois anos, junto a fornecedores), restrito, ainda, a somente cerca de $7 \%$ do total de empresas subcontratadas (a intenção da empresa, segundo seu executivo entrevistado é de expandir rapidamente esse tipo de interligação com seus fornecedores, dado que tal programa se iniciou há apenas 2 anos, aproximadamente). 


\subsubsection{Aspectos Jurídicos}

Em relação aos aspectos jurídicos/legais, entendidos aqui como aqueles referentes ao tipo e à duração dos contratos de fornecimento, especificamente, não há um consenso entre as empresas analisadas. Em geral, os contratos de longa duração praticamente inexistem. Quando muito se estabelece algum tipo de contrato, cujo teor poderia ser entendido (grosso modo) como um "documento de intenções" de fornecimento.

Na prática, contudo, são estabelecidos em conjunto (montadora e fornecedores) um "plano" de fornecimento de 90 dias (como no caso da MTD-2), que se desdobra em "programações" de entrega mensal, quinzenal ou semanal, conforme o tipo de item negociado. Em outros casos (como na prática da MTD-1), há uma diferenciação de tratamento no aspecto contratual, em função da capacitação e da "idoneidade" do fornecedor, sendo que aqueles que já atingiram a meta de pontuação pré-estabelecida pela "empresa-mãe" (meta esta definida a partir dos critérios anteriormente citados de preços, prazos de entrega, qualidade e assistência técnica) passam a obter o privilégio de contratos mais longos (geralmente 1 a 2 anos). Já aqueles que ainda não atingiram tal "meta", passam a receber um apoio do contratante no sentido de um "crescimento orientado".

\subsubsection{Aspectos Institucionais}

Finalmente, com relação à participação do Estado (em seus vários níveis de atuação), no sentido de estimular a prática de "desverticalização" das empresas montadoras, pode-se afirmar que praticamente todas desconhecem a existência de qualquer dispositivo institucional, especificamente criado para tal finalidade.

Paralelamente, porém, várias empresas entrevistadas observaram que o PBQP (Programa Brasileiro de Qualidade e Produtividade) estimula, de forma indireta, as estratégias de "desverticalização/terceirização" das grandes empresas, a partir de apelos para que as empresas atinjam um maior grau de flexibilidade e de agilidade, através de estruturas (operacionais e administrativas) mais "enxutas". Ainda neste aspecto, foi mencionado por uma empresa (MTD-2), a atuação do SEBRAE como um órgão de apoio para a maior capacitação dos fornecedores de menor porte, que, geralmente, não possuem condições financeiras para contratarem profissionais e/ou empresas de consultoria para tal finalidade.

\subsection{Grupo 2 - Autopeças}


Foram pesquisadas 8 empresas deste grupo. De uma maneira geral, as estratégias de "desverticalização/terceirização" das empresas fornecedoras de autopeças do 10. nível de subcontratação estão em um estágio relativamente mais atrasado do que as das montadoras. Há apenas uma exceção: um fabricante de rolamentos com mais de 80\% de terceirização por tradição da própria matriz.

Cabe destacar, em tempo, que a grande maioria das empresas que estão neste nível de subcontratação são empresas de capital estrangeiro, pertencentes a grandes grupos transnacionais com atuação em vários países industrializados e com uma linha de produtos bastante diversificada, que envolve, em sua grande maioria, produtos complexos, com elevado conteúdo tecnológico (caixas de câmbio, sistemas de freios, amortecedores, rolamentos, barras de direção, etc.)

Um dos principais obstáculos que se apresentam a essas empresas, no sentido de não acelerarem o processo de terceirização, encontra-se no fato de que muitas delas se defrontam, ainda, com a dificuldade básica de definição do seu verdadeiro "negócio central". Entretanto, a grande maioria das empresas analisadas afirmaram já possuírem uma estratégia de "desverticalização" definida pela alta direção da empresa. Em alguns casos, a estratégia é definida a partir de um colegiado, composto por membros da alta direção, gerentes de unidades de negócio/departamentos e responsáveis pelas áreas de suprimentos.

Todas as empresas dessa amostra afirmaram estar buscando algum tipo de "parceria". Entretanto, parece que há ainda muito pouca clareza quanto aos limites entre "parceria" e "terceirização", pois que os "parceiros" citados vão desde fornecedores já existentes até antigos funcionários da empresa que passaram a prestar algum tipo de serviço (ferramentaria, manutenção, ...) à organização da qual foi funcionário por algum tempo.

Quanto aos critérios adotados para se estabelecer algum tipo de parceria, foram enfatizados os seguintes (por ordem de prioridade):

10.) Custos menores dos "parceiros" (com menores exigências de novos investimentos).

2o.) Melhor qualidade dos serviços e/ou produtos fornecidos pelos "parceiros".

3o.) Maior "focalização no negócio".

Ainda quanto à estratégia de terceirização, percebeu-se que, na maioria das empresas analisadas, tal estratégia se restringe aos serviços de apoio ou a "atividades-meio" que não agregam valor diretamente ao produto final, tais como: serviços de limpeza, de transporte de pessoal, de segurança, de alimentação dos funcionários (restaurantes) e em alguns casos (como por exemplo o da empresa ATP1) serviços de consultoria nas áreas de conservação de energia e de meio ambiente, e serviços de Organização \& Métodos (no caso da ATP-9). 
Há que se destacar, porém, o fato de que algumas empresas (ATP-2) já estão desenvolvendo planos de "desverticalização/terceirização" de fases do próprio processo produtivo, em função do baixo grau de especialização tecnológica que estas fases requerem (laminação, retífica, tornearia, etc). Em outros casos, ainda, buscase, também, a subcontratação de algum tipo de serviço mais especializado, tais como os relativos a de "modelagem" para fundição e de ferramentaria. Em conseqüência, a nova situação da empresa (com maior grau de "focalização" em seu negócio principal) passa a viabilizar maiores investimentos na "especialização tecnológica" dos processos remanescentes, que podem ser traduzidos, por exemplo, em uma aceleração do processo de automatização destes processos.

Foi citada também a existência de uma maior resistência em se "terceirizar" as atividades relacionadas às áreas de sistemas e processamento de dados, em função da necessidade de segurança das informações. Já há, no entanto, a subcontratação de alguns aplicativos e de "softwares" específicos junto a empresas especializadas ('softhouses'), assim como a subcontratação de serviços de treinamento em informática para os funcionários da empresa (no caso, por exemplo, da ATP-8).

Do conjunto de peças e componentes que compõem o produto final, a porcentagem do valor total agregado que é adquirido de terceiros varia muito: desde mais do que 70\% (incluindo fornecedores e importação), como no caso da ATP-2, até $50 \%$ como no caso da ATP-7 (empresa que ainda se defronta com o problema básico da definição do seu "negócio central".

Do ponto de vista dos motivos que levaram as empresas a possuírem uma estrutura organizacional mais verticalizada desde a época de sua instalação no Brasil, praticamente todas elas concordam com a explicação de que na época (35 a 45 anos atrás) não havia fornecedores confiáveis/capacitados, quanto à qualidade de seus produtos, aos prazos de entrega e, principalmente, quanto ao nível de preço desejado (próximo aos níveis internacionais). Em alguns casos, ATP-1, contudo, havia uma certa "ideologia industrial", predominante até os anos mais recentes, de que "a força de fazer internamente é o que dá legitimidade para a empresa". Atualmente, entretanto, essa "ideologia" referente a um maior grau de verticalização das empresa de autopeças, passou a ser fortemente questionada pelas montadoras de veículos, que passam a pressionar constantemente as fornecedoras de autopeças sobre os custos (embutidos nos preços da peças/componentes) decorrentes dessa "ideologia".

A maioria das empresas de autopeças que compõem a amostra pesquisada, afirmou que há a intenção de se desenvolver novos fornecedores, assim como capacitar os antigos, em alguns casos, através de treinamento técnico e gerencial (TQM, CEP, ...). Nesse sentido, a maioria das empresas desse nível da "pirâmide de subcontratação" adota algum critério para classificar seus fornecedores. 
Por outro lado, entretanto, praticamente nenhuma das empresas tem o hábito de financiar o "investimento inicial" da nova subcontratada sendo que, no máximo, oferecem algum tipo de ferramental e de desenhos das peças solicitadas.

Há um consenso quanto à sua busca no sentido do aprimoramento da qualidade das peças/componentes de fornecedores já existentes, através de programas de "Qualidade Assegurada", como os do tipo "ISO 9000", e em vários casos identificouse que mais de $70 \%$ do número de sub-fornecedores (2o. nível da pirâmide) já são empresas "certificadas".

A maioria das empresas de autopeças do 1o. nível da pirâmide não busca promover, pelo menos de forma deliberada, uma concorrência entre seus subfornecedores, embora isto possa ocorrer (como no caso da ATP-1) nos casos de fornecimento de ítens novos. Nestes casos, a empresa contratante estabelece um certo "Plano de Redução de Custos" para provocar um maior acirramento na concorrência entre as subcontratadas.

Praticamente todas as empresas de autopeças desta amostra mantêm seus respectivos fornecedores informados sobre a programação da produção (em geral para um horizonte de tempo de até 3 meses) e, principalmente, sobre eventuais alterações que venham a ocorrer nessas programações. Nos casos onde há a necessidade de cancelamento de pedidos junto aos sub-fornecedores (do 3o nível da "pirâmide") a maioria das empresas optam por algum tipo de "negociação". Em outros casos de relacionamento mais "sincronizado" entre os fabricantes de autopeças e seus subfornecedores (caso da ATP-3) os programas de entrega são elaborados semanalmente e a contratante só decidiu "cortar" algum pedido a partir da 5a semana da programação, o que propicia uma ampla margem de negociação entre a empresa cliente e o subfornecedor.

Quando se questiona as empresas sobre quais têm sido as razões/justificativas que mais influenciam as suas estratégias de "terceirização" as respostas mais freqüentes recaem sobre a busca de maior flexibilidade nas suas operações e, de forma correlata, a necessidade de "centralizar o foco de sua produção"; em um nível logo abaixo, a prioridade apontada recai sobre a necessidade de redução dos custos de mãode-obra, principalmente nos níveis de supervisão e de média gerência. Algumas empresas, entretanto, chegaram a mencionar, também como prioritário, a necessidade de redução de custos fixos, referentes às instalações, equipamentos, etc., sendo que em alguns casos inclusive, já se desativou (ainda recentemente) uma linha completa de produção, correspondente a $15 \%$ da capacidade produtiva total de uma fábrica (empresa ATP-2).

Apesar de que a grande maioria das empresas analisadas neste grupo tenham mencionado não ter enfrentado qualquer problema em relação a algum tipo de influência dos sindicatos de trabalhadores em seus planos/programas de "terceirização", algumas delas chegaram a mencionar a busca de "redução de riscos trabalhistas" como sendo uma das razões para a empresa adotar tal estratégia. Neste sentido, ainda, há que se mencionar o fato de que na grande maioria das empresas desta amostra, que já estão envolvidas com alguma estratégia mais planejada de "desverticalização", observou-se significativa redução no quadro de funcionários 
nos últimos anos (30\%, em média) . Em alguns casos extremos, essa redução do efetivo chegou a atingir $41 \%$, nos últimos 4 anos.

Paralelamente à tendência de redução do número total de funcionários, as empresas deste grupo que optaram por algum tipo de estratégia de "desverticalização" realizaram, também, significativas alterações na própria estrutura organizacional da empresa, com fortes reduções do número de níveis hierárquicos. Em um dos casos mais significativos desta tendência de 'downsizing' uma empresa (a ATP-8) reduziu de 12 para apenas 5 o número de níveis hierárquicos.

No aspecto referente à perspectiva de redução do número de fornecedores por tipo de item comprado de terceiros, todas as empresas de autopeças entrevistadas, praticamente, concordam com a necessidade de redução deste número. Porém, quanto ao número exato de sub-fornecedores ideal há, ainda, alguma divergência entre as empresas. Praticamente todas concordam que 2 fornecedores por tipo de peças/componentes mais complexos (ou seja, aqueles obtidos através de processos de fabricação mais complexos e, portanto, mais caros, em geral) seria o numero ideal, dado que a opção de "fornecedor único" seria altamente arriscado nesses casos; já para os ítens de "uso genérico" (porcas, parafusos, arruelas, etc.) a opção por um único fornecedor passa a ser bem vista por várias empresas, embora, atualmente, a maioria das empresas deste grupo trabalhem, ainda, com uma média de 3 fornecedores por item.

Quanto aos critérios utilizados para a distribuição de compras junto às empresas subcontratadas, a quase totalidade das empresas analisadas optou pelo item "qualidade", principalmente no que se refere às matérias-primas. Em segundo lugar a opção foi para os ítens "preço" e "pontualidade na entrega", vindo, finalmente, o item "assistência técnica". Entretanto, nos casos de compras de peças mais complexas (mais caras, em geral) o item "preço" passa a ganhar prioridade.

\subsubsection{Sistemas de Informação}

Com relação à existência ou não de "sistemas interligados de informação" entre as empresas de autopeças do 1o nível da "pirâmide de subcontratação" com as de 2o ou níveis inferiores, não foi encontrada qualquer empresa (através da amostra específica deste estudo) que possuisse algum tipo de sistema 'on line' de informações e/ou sistemas de "CAD Integrado" com algum sub-fornecedor, embora, já na opinião de alguns executivos entrevistados, esta deverá ser uma tendência inexorável. Entretanto, em função da atual crise econômica, qualquer intenção de investimentos nesse sentido fica, evidentemente, prejudicada.

\subsubsection{Aspectos Jurídicos}


Neste item da pesquisa utilizou-se do mesmo entendimento dos "aspectos jurídicos/legais" da análise anterior realizada sobre o grupo das montadoras, ou seja, concentrou-se maior atenção para as questões em torno do tipo de "contrato de fornecimento" utilizado entre as empresas. Assim sendo, cabe salientar, inicialmente, que a maioria das empresas entrevistadas prefere omitir-se de responder a respeito do tipo de contrato social escolhido nos casos de subcontratação ou "terceirização". Aquelas, porém, que responderam a este item limitaram-se a afirmar que são utilizados os contratos do tipo "padrão e simples", e uma delas (ATP-5) afirmou que adota como instrumento jurídico mais adequado nestes casos um "termo de anuência à locação de serviços".

Entretanto, no aspecto dos prazos utilizados nos contratos de prestação de serviços ou de fornecimentos de peças, a tendência mais freqüente (encontrada neste grupo de empresas) foi a seguinte:

Contratos de até 1 ano: Utilizados com maior freqüência nos casos de prestação de "serviços gerais", que envolvem, em geral, um elevado número de fornecedores e/ou "terceiros" (tais como, serviços de limpeza, de manutenção predial, etc.).

Contratos de 1 a 2 anos: Nos casos relativos a algum tipo de "serviços especiais", tais como no caso de serviços de informática.

Contratos acima de 2 anos: Contratos mais longos são utilizados, via-de-regra, nos casos dos serviços prestados por "terceiros" mais confiáveis e tradicionais, como nos casos dos serviços de "assistência médica" (como, por exemplo, para a ATP-5), ou de serviços de "transporte de pessoal", restaurante e de manutenção de computadores e de centrais de PABX (no caso da ATP-2).

Vale salientar, também, que os contratos de longa duração (acima de dois anos) são praticados em casos de peças/componentes importados, em função, certamente, das exigências do próprio fornecedor estrangeiro.

\subsubsection{Aspectos Institucionais}

Analogamente ao que foi feito para o grupo de empresas montadoras (Grupo 1) serão analisados alguns dos aspectos relativos às possíveis influências das políticas públicas sobre as estratégias de "desverticalização/terceirização" das empresas de autopeças.

Em primeiro lugar, quando se questiona se há, atualmente, algum tipo de "mecanismo legal" que estimule ou facilite as estratégias de "terceirização" das grandes empresas de autopeças no Brasil, a quase totalidade das empresas analisadas preferiu afirmar que desconhecem a existência de tais "mecanismos". Algumas delas, entretanto, chegaram a concordar com o fato de que as constantes oscilações do nível de atividade econômica (produtiva, melhor dizendo) obrigam as empresas do setor industrial a adotarem ações conflitantes, ora no sentido de contratar, ora no de demitir pessoal (principalmente mão-de-obra direta), o que por si só se constitui em um elemento pertubador de qualquer planejamento de longo prazo, em especial, para um plano de "desverticalização/terceirização". Em outros casos (como revelado pela ATP5), foi citado o fato de que nesse aspecto de pessoal há, ainda, "muitos embates 
judiciais e entraves trabalhistas, que passam pelas mesas de negociação de tribunais de trabalho".

Complementando esta questão, as "medidas institucionais" que, segundo as empresas analisadas, deveriam ser adotadas para que houvesse maiores estímulos à "terceirização" e à busca de parcerias, estariam relacionadas, principalmente, aos seguintes aspectos:

10) Promoção de uma maior estabilidade (macro) econômica, que viabilizasse maior confiança para a ocorrência de maiores investimentos produtivos.

20) "Modernização das leis trabalhistas", que deveriam incluir em toda e qualquer pauta de negociação o tema "terceirização"

30) Melhorar o nível de educação da população em geral e, principalmente, daquela parcela de trabalhadores industriais, através de crescentes investimentos na "formação profissional/tecnológica" de forma moderna e atualizada, além da "formação nas áreas de liderança, produtividade e qualidade".

40) Maiores incentivos à produção de bens que se baseiam em "parâmetros de competição internacional".

\section{Considerações Finais}

Desde a sua implantação no Brasil, nos anos 50, a indústria automobilística vem praticando, em maior ou menor grau, algum tipo de "estratégia de desverticalização", através do tradicional sistema de subcontratação de peças e componentes de um grande número de fornecedores. Porém, a maior parte de peças de maior complexidade e, conseqüentemente, maior conteúdo tecnológico, eram produzidos internamente ('in house'), inicialmente.

Ainda hoje (início dos anos 90) há poucas empresas (tanto montadoras como empresas de autopeças de primeiro nível) que decidiram elevar seus índices de "desverticalização", aumentando para isso o grau de 'outsourcing' junto a "terceiros". Isto se explica, principalmente, pelo fato de que para a maioria das empresas montadoras e de autopeças do primeiro nível de subcontratação ainda não existe uma rede de fornecedores totalmente confiáveis, isto é, que tenham a capacidade suficiente para fornecer produtos com "qualidade assegurada". A conseqüência imediata desta situação se revela em atitudes isoladas por parte de algumas grandes empresas contratantes no sentido de buscarem capacitar alguns de seu fornecedores de componentes mais críticos, através de algum tipo de suporte técnico/gerencial.

Em geral, pode-se constatar ainda, que a opção pelo 'globalsourcing' (fornecimento internacional) vem se constituindo em uma alternativa cada vez mais atraente, principalmente para as "empresas-mãe" (montadoras), embora essa prática de fornecimento não tenha, ainda, se difundido em maior escala, tanto em função da existência de algumas restrições de importação, quanto em função de uma certa "inércia" das próprias empresas interessadas.

Quanto ao padrão de relacionamento entre as empresas montadoras e fornecedoras de autopeças pertencentes ao primeiro nível da "pirâmide de subcontratação", pode-se verificar que tal relacionamento tem se tornado menos 
conflitivo, ao longo dos últimos anos (após a "década perdida"). O mesmo, entretanto, não se pode afirmar quanto ao relacionamento das empresas de autopeças deste primeiro nível com as empresas pertencentes aos níveis inferiores da "pirâmide", dado que tal relacionamento ainda está marcado por constantes ameaças de abandono de "contratos", atrasos na entrega de pedidos, altos índices de peças com baixa qualidade (rejeitadas, em geral), ou seja, por um tipo de relacionamento baseado na antiga "estratégia da saída"(HELPER, 1991a, b, c).

Confrontando-se as análises dos casos apresentados anteriormente ("pesquisa de campo") com a tipologia proposta por CHANARON et al. (1993), pode-se concluir que os princípios que norteiam a modalidade de suprimento/aprovisionamento de peças e componentes no complexo automobilístico brasileiro estão, via-de-regra, mais próximos do "modo de subcontratação tradicional", ainda que em alguns casos isolados possa se encontrar características do modo "de mercado". Tais princípios, entretanto, estão ainda muito aquém do "modo de parceria", considerado aqui o "modelo" de fornecimento/aprovisionamento mais desenvolvido e eficiente para os padrões de excelência e de competição mundial.

\section{Referências Bibliográficas:}

CHANARON, J.J. et al.: "Constructeurs/Fornisseurs: Specifites et Dynamique D'Evolution des Modes Relationnels". In: Journées Internationales du GERPISARI, Paris, juin/1993.

HELPER, S.: Strategy and Irreversibility in Supplier Relations: The case of the US Automotive Industry. Case Western Reserve University, Cleveland, 1991a.

HELPER, S.: Supplier Relations and Investment in Automation: Results of Survey Research in the US Auto Industry. Case Western Reserve University, Cleveland, 1991b.

HELPER, S.: Incentives for Supplier Participation in Product Development: Evidence from the US Auto Industry. Case Western Reserve University, Cleveland, 1991c.

HOFFMAN,J. \& KAPLINSKY,R.: Driving Force:The Global Reestructuring of Technology, Labor and Investment in the Automobile Industry. West View Press, Bolder Colorado, 1989.

WOMACK, J.P. et al.: The Machine that Changed the World. International Motor Vehicle Program, M.I.T. Program, M.I.T., 1990. 


\title{
VERTICAL DESINTEGRATION/OUTSOURCING AND THE SUBCONTRACTING RELATIONS IN THE BRAZILIAN AUTOMOBILE INDUSTRY
}

\begin{abstract}
The aim of this study is to investigate, based on the context of the global industry restructuring, the main factors which have induced the process of vertical desintegration of the larger companies in the brazilian automobile industry. It involves the consequent increase of outsourcing process by the same companies. Thirteen case studies are presented (5 automakers and 8 autoparts companies) with the purpose of identifying the tendency of these fenomena (vertical desintegration / outsourcing process) within the brazilian automobile complex. These case studies provide some evidence which allow us to reach some conclusions, for instance: the relationship between the automakers and the autoparts companies belonging to the first step of the "subcontracting pyramid" has become less conflicting. But the relationship between the autoparts companies ("first step") and their suppliers (second, third,...steps) is still based upon the "exit strategy", representing a lot of problems to both sides (e.g. : delay in delivers, high rate of low quality products, etc.). The tendency in the forthcoming years is to improve the relationship between suppliers and costumers, mainly between the automakers and these companies that produce most complex autoparts (such engine, gearboxes, brake systems, etc.). The same kind of relationship, when it comes to lower steps as the "subcontracting pyramid", seems to be more difficult.
\end{abstract}

Key-words: vertical desintegration, outsourcing, subcontracting. 